\title{
A High Performance Maximum Power Point Tracker for Photovoltaic Power System Using DC-DC Boost Converter
}

\author{
Moshiur Rahman Sourov ${ }^{1}$, Ummee Tania Ahmed $^{1}$, Mirza Golam Rabbani ${ }^{2}$ \\ ${ }^{1}$ Department of Electrical and Electronics Engineering, University of Asia Pacific, Dhaka, Bangladesh \\ ${ }^{2}$ Department of Electrical and Electronics Engineering, Rajshahi University of Engineering \& Technology, \\ Bangladesh
}

\begin{abstract}
To extract the maximum power from a photovoltaic (PV) energy system, the real-time maximum power point (MPP) of the PV array must be tracked closely. The non-linear and time-variant characteristics of the PV array and the non-linear and non-minimum phase characteristics of a boost converter make it difficult to track the MPP for traditional control strategies. In this paper, the design of a maximum power point tracker for the solar $\mathrm{PV}$ module is presented. The design consists of a DC to DC Boost converter for impedance matching to transfer the maximum power controlled by the Duty cycle. The incremental Conductance method with some modification is used as an algorithm to track the maximum power point of the PV array. By using this algorithm the MPPT is able to track the maximum power of the $P V$ array quickly under rapidly changing intensity of sunlight.
\end{abstract}

Keywords - Maximum Power Point Tracker (MPPT), Solar Photovoltaic (PV) Module, DC-DC Boost converter, Incremental Conductance method, Impedance Matching.

\section{INTRODUCTION}

Nowadays, photovoltaic (PV) systems are used as energy source in many cases. Most commonly applied PV systems can be found in remote and rural areas where no public grid is available. Photovoltaic cells offer consumers the ability to generate electricity in a clean, quiet and reliable way. But the efficiency of the solar PV module is very low. Due to the high cost of solar cells, a maximum power point tracker is needed to operate the PV array at its maximum power point. Thus the maximum power extracted from the PV generator depends strongly on three factors: insolation, load profile (load impedance) and cell temperature (ambient temperature). To get the maximum power from PV, a maximum power point tracker (MPPT) is used. Variation in lighting intensity causes these trackers to deviate from the maximum power point. When lighting conditions change, the tracker needs to respond within a short amount of time to the change to avoid energy loss [1]-[2]. This paper represents the Impedance Matching Technique of DC-DC Boost converter to transfer the maximum power and modified the Incremental Conductance algorithm to track the maximum power point for rapidly changing atmospheric condition. The rest of this paper is organized as follows. Section II introduces equivalent circuit of a solar cell. Section III describes the characteristics of the solar cell. Section IV explains boost converter and impedance matching. Section $\mathrm{V}$ describes the method of maximum power point tracking. Calculations and conclusions are finally discussed in the last section.

\section{SOLAR CELL EQUIVALENT CIRCUIT}

To understand the electronic behavior of a solar cell, it is useful to create a model which is electrically equivalent, and is based on discrete electrical components whose behavior is well known. An ideal solar cell may be modeled by a current source in parallel with a diode; in practice no solar cell is ideal, so a shunt resistance and a series resistance component are added to the model. The solar cell is a nonlinear device and can be represented as a current source model, as shown in figure-1. $R_{\text {shcell }}$ is the equivalent shunt resistance of the solar cell whose value is usually very large. To simulate the suggested PV system, it is necessary to have a mathematical model to express a typical current-voltage I-V characteristic of PV arrays. 


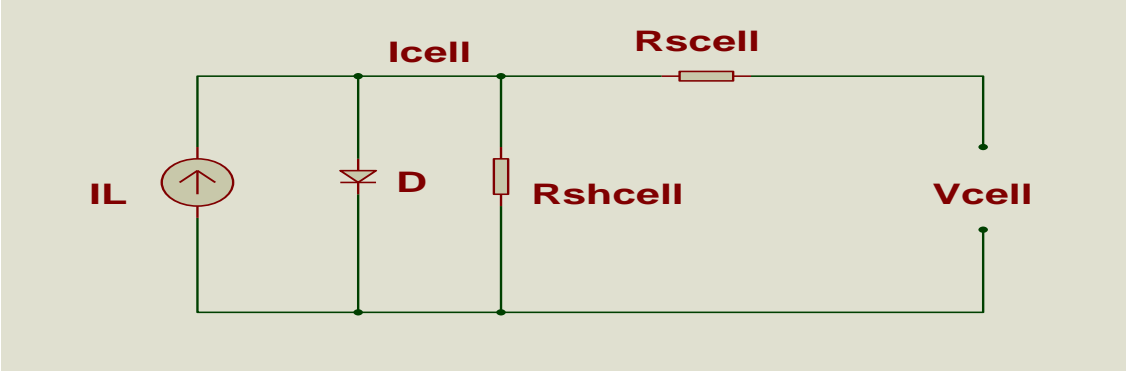

Figure:1 equivalent Circuit of solar cell

For a single solar silicon cell, the nonlinear I-V characteristic is

$$
I_{\text {cell }}=I_{L}-I_{o}\left[\exp \left(G\left(V_{\text {cell }}+I_{\text {cell }} R_{\text {cell }}\right)\right)-1\right]-\frac{V_{\text {cell }}+I_{\text {cell }} R_{\text {cell }}}{R_{\text {shcell }}}
$$

Where, Icell $=$ Cell output current(A), $I_{L}=$ light-generated current(A), Io = cell saturation current (A)

Vcell $=$ cell output voltage $(\mathrm{V})$, Rscell $=$ cell series resistance $(=0.025 \Omega)$, Rshcell $=$ cell shunt resistance

And,

$$
G=\frac{q}{A i K T}
$$

Where,

$\mathrm{Ai}=$ ideality factors $(=1.92), \mathrm{K}=$ Boltzmann's constant $\left(=1.38 \times 10^{-23} \mathrm{~J} / \mathrm{K}\right)$, $\mathrm{q}=$ electronic charge $\left(=1.6 \times 10^{-19} C\right), \mathrm{T}=$ cell temperature

And,

$$
I_{L}=\left[I_{S C}+K_{I_{S C}}(T-28)\right] \times \frac{R \text { ad }}{10 O O}
$$

Where,

$$
\text { Isc }=\text { cell short circuit current at } 28 \mathrm{C} \text { and } 1000 \mathrm{~W} / \mathrm{m}^{2}(=2.52 \mathrm{~A})
$$

$$
K_{I_{S C}}=\text { short circuit current temperature coefficient (=0.0017 A/C) }
$$

$\mathrm{Rad}=$ cell illumination, $\mathrm{W} / \mathrm{m}^{2}\left(1000 \mathrm{~W} / \mathrm{m}^{2}=100 \%\right.$ illumination $)$

And,

$$
I o=\operatorname{Ior}\left(\frac{T}{T r}\right)^{3} \exp \left[\frac{q E_{G O}}{A i K}\left(\frac{1}{T r}-\frac{1}{T}\right)\right]
$$

Where,

Ior $=$ reverse saturation current at $\operatorname{Tr}\left(=19.9693 \times 10^{-6} \mathrm{~A}\right)$

$\mathrm{Tr}=$ reference temperature $(=301 \mathrm{~K}), \quad E_{G O}=$ band gap for silicon $(=1.11 \mathrm{ev})$

The array temperature $\mathrm{T}$ is given, approximately, by the relation

$$
\mathrm{T}=\text { Tair }+0.3 \times \operatorname{Rad} \% \quad \text { (5) }
$$

Tair $=$ ambient temperature, ${ }^{0} \mathrm{C}$

Where,

The PV arrays are built up with series and/or parallel connected combinations of solar cells. Therefore, for the array of $n_{s} \times n_{p}$ (i.e. cells in series by panels in parallel) the current equation is

$$
I p v=n_{p} I_{L}-n_{p} I o\left[\exp \left(G\left(\frac{V p v+I p v R s}{n_{s}}\right)\right)-1\right]-\frac{V p v+I p v R s}{R s h}
$$

Where, $\quad \mathrm{Ipv}=\mathrm{PV}$ array output current, $\mathrm{A}, \mathrm{Vpv}=\mathrm{PV}$ array output voltage, $\mathrm{V}, n_{s}=$ number of cells connected in series, $n_{p}=$ number of cells connected in parallel, Rs $=\mathrm{PV}$ array series resistance $(\Omega), \operatorname{Rsh}=\mathrm{PV}$ array shunt resistance $(\Omega)$

$$
\begin{aligned}
& I p v=n_{p} \text { Icell }------------------------------(7) \\
& V p v=n_{s} \text { Vcell }-----------------------------(8) \\
& R s=R \operatorname{scell} \frac{n_{s}}{n_{p}}-----------------------------(9) \\
& R s h=R s h c e l l \frac{n_{s}}{n_{p}}----------------------------(10)
\end{aligned}
$$


Hence, the shunt resistance Rshcell is much greater than the series resistance Rscell. The last term in equation (6) becomes very small with respect to the other terms. Therefore, the last term will be neglected, as it will not cause a large error in the PV array model; hence, Equation (6) can be modified to the form.

$$
I p v=n_{p} I_{L}-n_{p} I o\left[\exp \left(G\left(\frac{V p v+I p v R s}{n_{s}}\right)\right)-1\right]
$$

\section{SOLAR CELL CHRECTERISTICS}

The current-voltage characteristic of a solar cell is non-linear, which makes it difficult to determine the maximum power point. Equation (11) was used in MATLAB to simulate the characteristic of a solar array. Figure -3 and figure -4 illustrates the simulated I-V and P-V characteristic of the solar array under a fixed temperature $\left(\mathrm{T}=25^{\circ} \mathrm{C}\right)$ and a fixed irradiance of $1000 \mathrm{~W} / \mathrm{m}^{2}$ respectively. The I-V and P-V characteristic for various irradiance at fixed temperature $\left(\mathrm{T}=25^{\circ} \mathrm{C}\right)$ are shown in figure-5 and figure- 6 respectively. Figure- 4 illustrates the operating characteristic curves of the solar array under a given insolation. It consists of two regions: one is the current source region, and the other is the voltage source region. In the voltage source region, the internal impedance of the solar array is low on the right side of the curve, and in the current source region, the internal impedance of the solar array is high on the left side of the curve. The MPP of the solar array is located at the knee of the curve..

For a solar cell, the non-linear relationship means the maximum power point has to be determined by calculating the product of the voltage and output current. In order to extract maximum power from the solar array, the solar array must always be operated at or very close to where the product of the voltage and output current is the highest. This point is referred to as the maximum power point (MPP), and it is located around the 'bend' or 'knee' of the I-V and P-V characteristic curves.
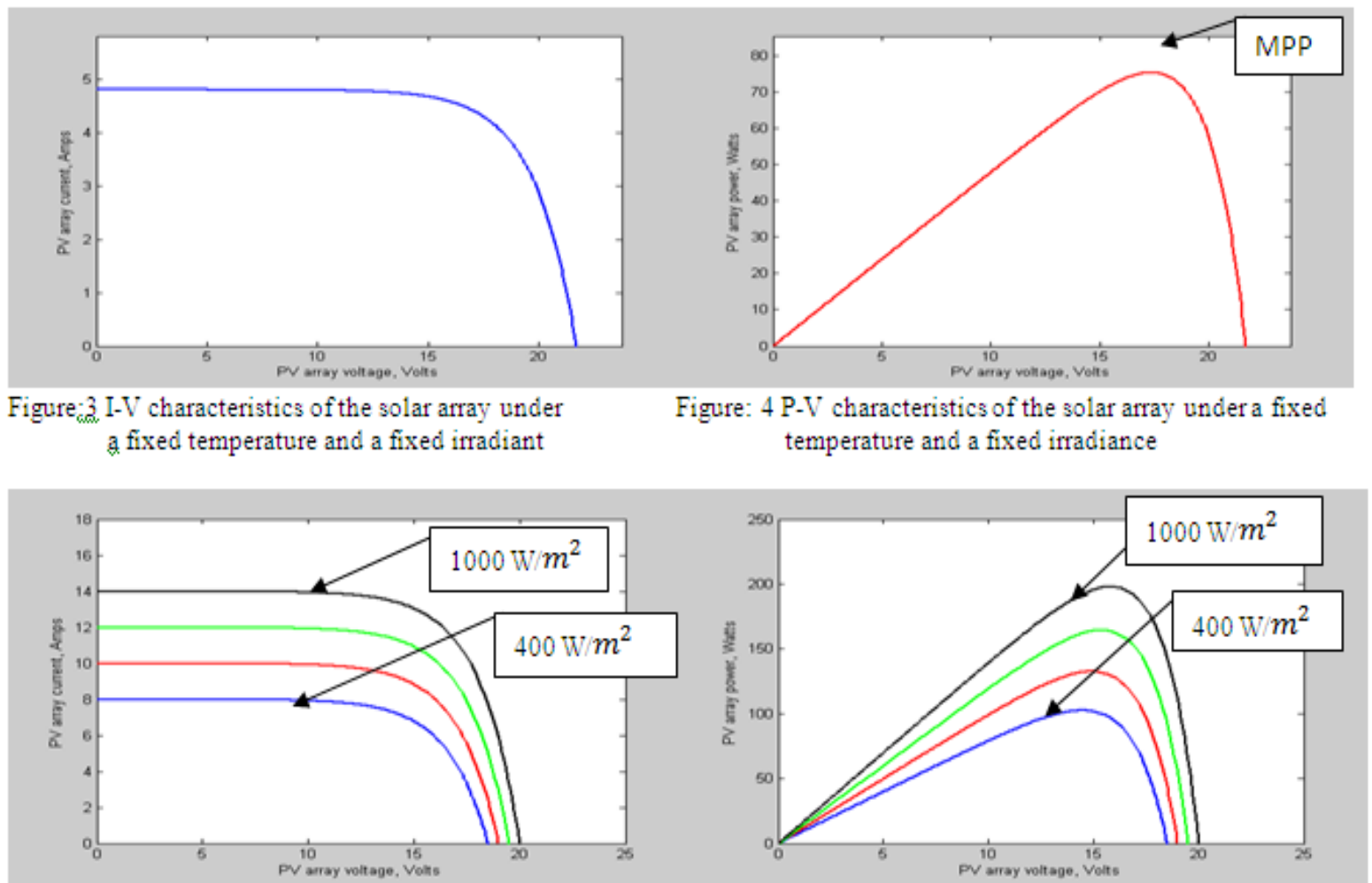

Figure-5. I-V characteristics of the solar array under a fixed Figure: 6 P.V characteristics of the solar array under a fixed temperature but different irradiance,

temperature but different irradiance

However, one of the reasons the solar panel operates more efficiency with decreasing temperature is due to the electron and hole mobility of the semiconductor material. As temperature increases, the electron and hole mobility in the semiconductor material decreases significantly [10]. The electron mobility for silicon at $25^{\circ} \mathrm{C}$ is about $1700 \mathrm{~cm} /$ volt-sec and will decrease to about a fourth of this value as temperature increases to $25^{\circ} \mathrm{C}$ and likewise the hole mobility decreases from about $600 \mathrm{~cm} /$ volt-sec at $25^{\circ} \mathrm{C}$ to $200 \mathrm{~cm} /$ volt-sec as temperature increases to $25^{\circ} \mathrm{C}$. While the higher reference temperature are not realistic operating conditions for a solar panel, it does show that electron and hole mobility decreases with increasing temperature. The band gap energy of semiconductor materials also varies with temperature. An increase in temperature will cause the band gap energy of the material to increase. With higher band gap energy, the electrons in the valance band will require 
more energy from the photons to move to the conduction band. This means that a lot more photons will not have sufficient energy to be absorbed by the electrons in the valance band resulting in fewer electrons making it to the conduction band and a less efficient solar cell.

Although irradiance is an important factor in determining the I-V characteristic of a solar panel, it is not the only factor. Temperature also plays an important role in predicting the I-V characteristic, and the effects of both factors have to be considered when designing a PV system. Whereas the irradiance mainly affects the output current, the temperature mainly affects the terminal voltage. Figure -7 and figure -8 shows the simulated $\mathrm{I}-\mathrm{V}$ and P-V characteristic for various temperatures at fixed irradiance of $1000 \mathrm{~W} / \mathrm{m}^{2}$ respectively.

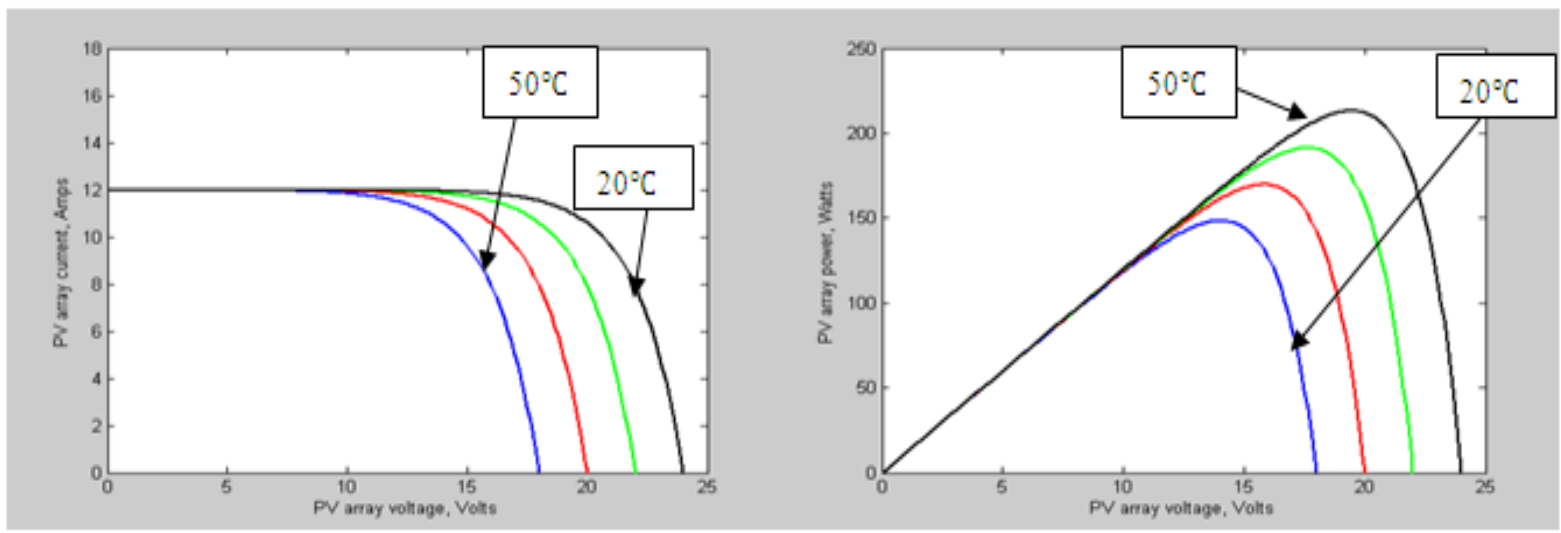

Figure: $7 . P-V$ characteristics of the solar array under a fixed irradiance but different temperature
Figure: 8 P.V characteristics of the solar array under a fixed irradiance but different temperature

It is to be mentioned that the conversion efficiency of the solar PV module is low of (10-17) \% [2]. Since the module efficiency is low, it is desirable to operate the module at the peak power point so that the maximum power can be delivered to the load under varying temperature and insolation conditions. Hence, maximization of power improves the utilization of the solar PV module. A maximum power point tracker (MPPT) is used for extracting the maximum power from the solar PV module and transferring that power to the load. According to the maximum power transfer theory, the power delivered to the load is a maximum when the source internal impedance matches the load impedance. A DC-DC converter (step up) can be used to serve the purpose of transferring maximum power from the solar PV module to the load. A DC-DC converter acts as an interface between the load and the solar PV module.

If the system required operating at or near the MPPs of the solar array, then the impedance seen from the converter input side (can be adjusted by PWM control signal) needs to match the internal impedance of the solar array. By changing the duty cycle the load impedance $\mathrm{Zi}$ as seen by the source is varied and matched at the point of the peak power with the source so as to transfer the maximum power

\section{BOOST CONVERTER AND IMPEDANCE MATCHING}

The Boost Converter, as shown in figure-9 is also known as the step-up converter. As implies, its typical application is to convert low input-voltage to a high output voltage.

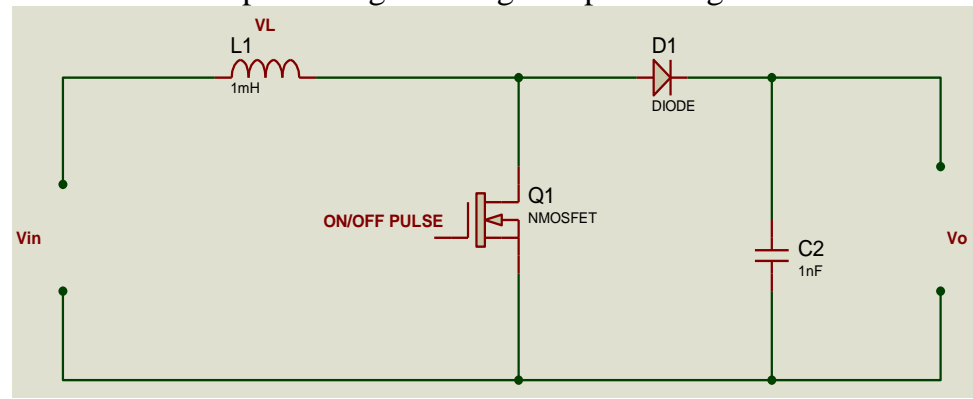

Figure:9 DC-DC Boost converters

During the first time interval DT of the switching period $\mathrm{T}$, the closed switch connects the input through the inductor to ground and current starts to flow, the current through the inductor increases and the energy stored in the inductor builds up. The diode is reversed biased so no inductor current flows through the load, thus isolating the output stage. After the switch is opened in the second time interval (1-D)T of the 
switching period, the output stage receives energy from the inductor as well as from the input. In steady state analysis, the output capacitor is assumed to be large to ensure a constant output voltage $V_{o}(t) \cong V_{o}$.

The boost converter is a DC equivalent of an $\mathrm{AC}$ transformer.

And,

The output current, Io $=(1-\mathrm{D}) \mathrm{Ii}$

The input current, $\quad \mathrm{Ii}=\mathrm{Io} /(1-\mathrm{D})$

The output voltage $\quad \mathrm{Vo}=\mathrm{Vi} /(1-\mathrm{D})$

And,

$$
\text { The input voltage } \quad \mathrm{Vi}=(1-\mathrm{D}) \mathrm{Vo}
$$

The equivalent resistance seen from the source is the ratio of input (source) voltage and input current.

$$
\begin{aligned}
& R i=\frac{V i}{I i}=\frac{(1-D) V o}{\frac{I o}{(1-D)}}=(1-D)^{2} \times \frac{V o}{I o} \\
& R i=(1-D)^{2} \times R_{L}---------
\end{aligned}
$$

From the above equation, we can say that the value of input impedance of the boost converter and load impedance can be matched by controlling the duty cycle. Moreover, if the system is required to operate at or near the MPPs of the solar array without changing the load resistance, the resistance seen from the converter input side (can be adjusted by changing the duty cycle) needs to match the load resistance [3].

\section{MAXIMUM POWER POINT TRACKING}

The maximum power point is obtained by introducing a converter in between the load and the solar PV module. The duty cycle of the converter changes till the peak power point is obtained.

According to equation (17) load resistances RL remains constant and by changing the duty cycle the input resistance Ri seen by the source is changed. So the resistance corresponding to the peak power point is obtained by changing the duty cycle.The figure- 10 shows the I-V characteristics and the maximum power point of a PV cell at a particular condition.

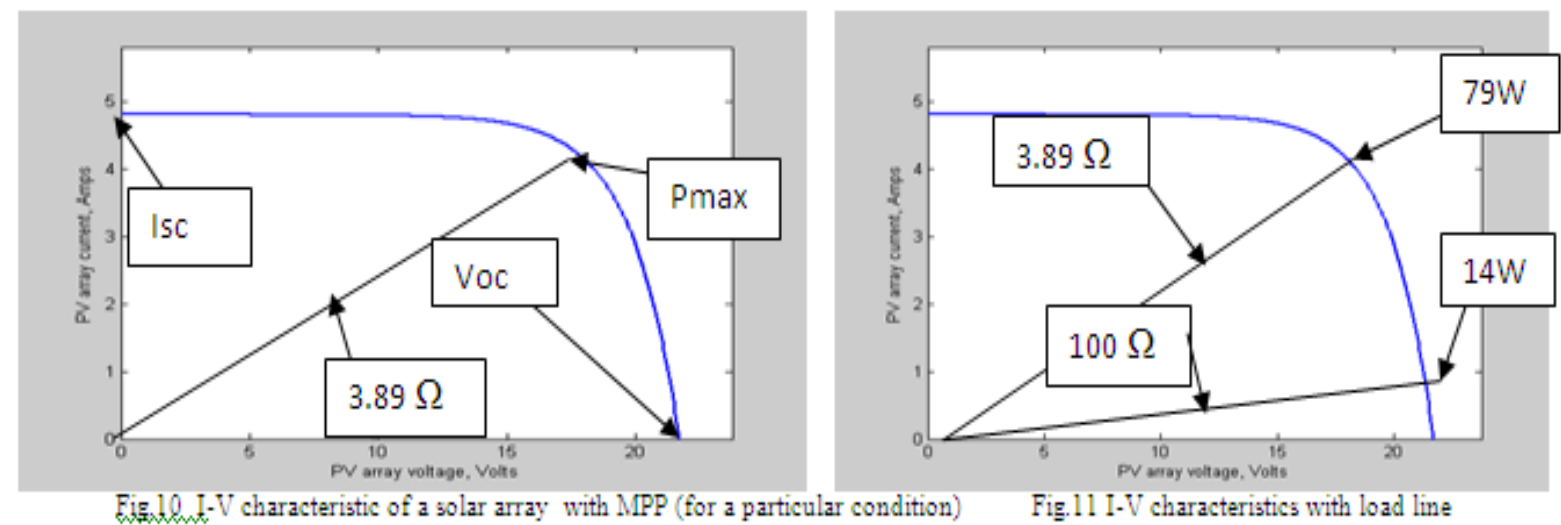

At this point the power (the product of voltage and current) provided by the PV cell reaches its maximum. That is also called peak power point. For this particular insolation and temperature level the maximum power approximately $79 \mathrm{~W}$ occurs at $17.5 \mathrm{~V}, 4.5 \mathrm{~A}$. For maximum power from panels at this solar intensity level, a load $\mathrm{RL}=17.5 \mathrm{~V} / 4.5 \mathrm{~A}=3.89 \mathrm{ohm}$ is required to attach with the panel. But as the sun's conditions change, the "maximum power resistance" also changes. When a $100 \mathrm{ohm}$ load is directly connected with the panel, only $14 \mathrm{~W}$ power is extracted which is shown by the figure- 11 . To extract the maximum power (79W) connects the boost converter between the panel and the load resistor, and uses D to modify the equivalent load resistance seen by the source. From equation (17)

$$
R_{\text {equiv }}=(1-D)^{2} \times R_{L}
$$

$$
(1-D)^{2}=\frac{\operatorname{Re} q u i v}{R_{L}} \text { or, }
$$

$$
\text { , so, } \mathrm{D}=1-\sqrt{ }(3.89 / 100), \mathrm{D}=0.8027
$$

Hence, when $\mathrm{D}=0.8027$ the $100 \mathrm{ohm}$ load resistor seen by the source is only $3.89 \mathrm{ohm}$ and corresponding system operating voltage is $17.5 \mathrm{~V}$ and current is $4.5 \mathrm{~A}$, which is the maximum power point for this condition.

The Incremental Conductance method is chosen as a tracking algorithm for MPPT. The disadvantage of the perturb and observe method to track the peak power under fast varying atmospheric condition is overcome by Incremental conductance method [7]. The algorithm makes use of the $\mathrm{P}=\mathrm{V}^{*} \mathrm{I} \quad$ (Where $\mathrm{p}=$ array power, $\mathrm{V}=$ array voltage, $\mathrm{I}=$ array current);

The fact that $\mathrm{P}=\mathrm{V} * \mathrm{I}$ and the chain rule for the derivative of products yields 


$$
\begin{aligned}
& \frac{d P}{d V}=\frac{d(V I)}{d V}=I \frac{d V}{d V}+V \frac{d I}{d V} \\
& \frac{d P}{d V}=I+V \frac{d I}{d V}------- \\
& \frac{1}{V} \frac{d P}{d V}=\frac{I}{V}+\frac{d I}{d V}------
\end{aligned}
$$

Let's define the source conductance: $\mathrm{G}=\mathrm{I} / \mathrm{V}$

And the source incremental conductance: $\Delta \mathrm{G}=\mathrm{dI} / \mathrm{dV}$

Depending on this equation the algorithm works.

At peak power point, $\frac{d P}{d V}=0$, or, $\frac{d I}{d V}+\frac{I}{V}=0$

If the operating point is to the right of the curve then we have

$$
\frac{d P}{d V}<0, \text { or, } \frac{d I}{d V}+\frac{I}{V}<0
$$

If the operating point is to the right of the curve then we have

$$
\frac{d P}{d V}>0, \text { or, } \frac{d I}{d V}+\frac{I}{V}>0
$$

Using equations (20-22) the algorithm works.

In general output voltage from a source is positive. Equation (19) explains that the operating voltage is below the voltage at the maximum power point if the conductance is larger than the incremental conductance, and vice versa. The job of this algorithm is therefore to search the voltage operating point at which the conductance is equal to the incremental conductance. This algorithm has advantages over perturb and observe in that it can determine when the MPPT has reached the MPP, where perturb and observe oscillates around the MPP. Also, incremental conductance can track rapidly increasing and decreasing irradiance conditions with higher accuracy than perturb and observe.

The program flow chart for this algorithm is shown in figure-13. The algorithm reads the value of current and voltage from the solar PV module. Power is calculated from the measured voltage and current. The value of voltage and power at $\mathrm{K}^{\text {th }}$ instant are stored. Then next values at $(\mathrm{k}=1)$ th instant are subtracted with the values from Kth instant. It is observed from the power voltage curve of the solar PV module that in the right hand side curve where the voltage is almost constant the slope of power voltage is negative $(\mathrm{dP} / \mathrm{dV}<0)$.

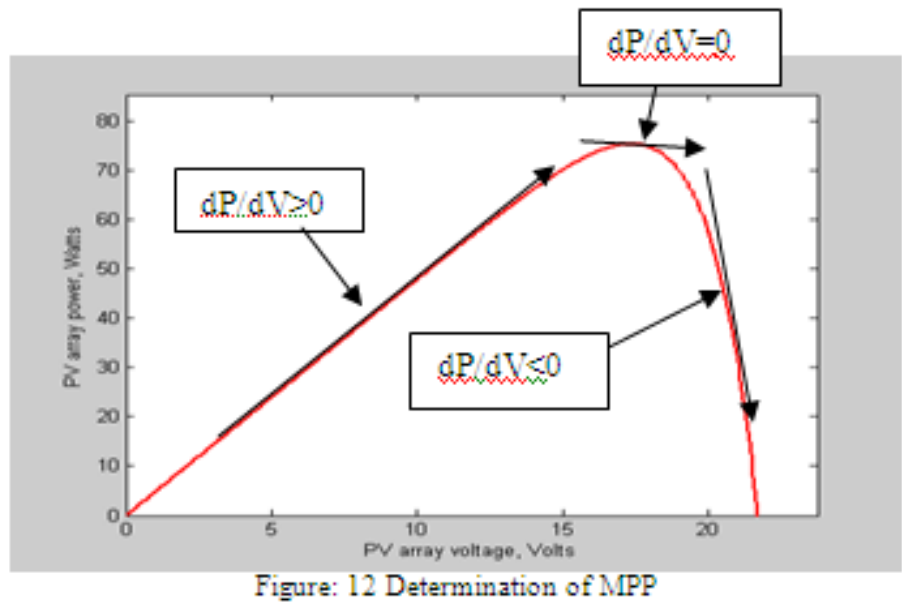

Where as in the left hand side the slope is positive $(\mathrm{dP} / \mathrm{dV}>0)$. The right side of the curve is for the lower duty cycle (nearer to unity). Depending on the value of $I+\frac{d \boldsymbol{I}}{d \boldsymbol{V}} \boldsymbol{V}$ the algorithm decides whether to increase the duty cycle or to reduce the duty cycle. In order to make the calculation practical for the $\mathrm{dP} / \mathrm{dV}$ term replaced by $\boldsymbol{I}+\frac{d \boldsymbol{I}}{d \boldsymbol{V}} \boldsymbol{V}$. If the system was operating at the MPP during the previous cycle, the incremental change of the operating voltage will be zero $\mathrm{dV}=0$. This would lead to a division by zero i.e. $I+\frac{d \boldsymbol{I}}{d V} \boldsymbol{V}$, which is impossible for calculation. To avoid this, the condition $\mathrm{dV}=0$ is checked first and led to another branch if true in the algorithm with further tests on possible changes of the panel's operating condition. 


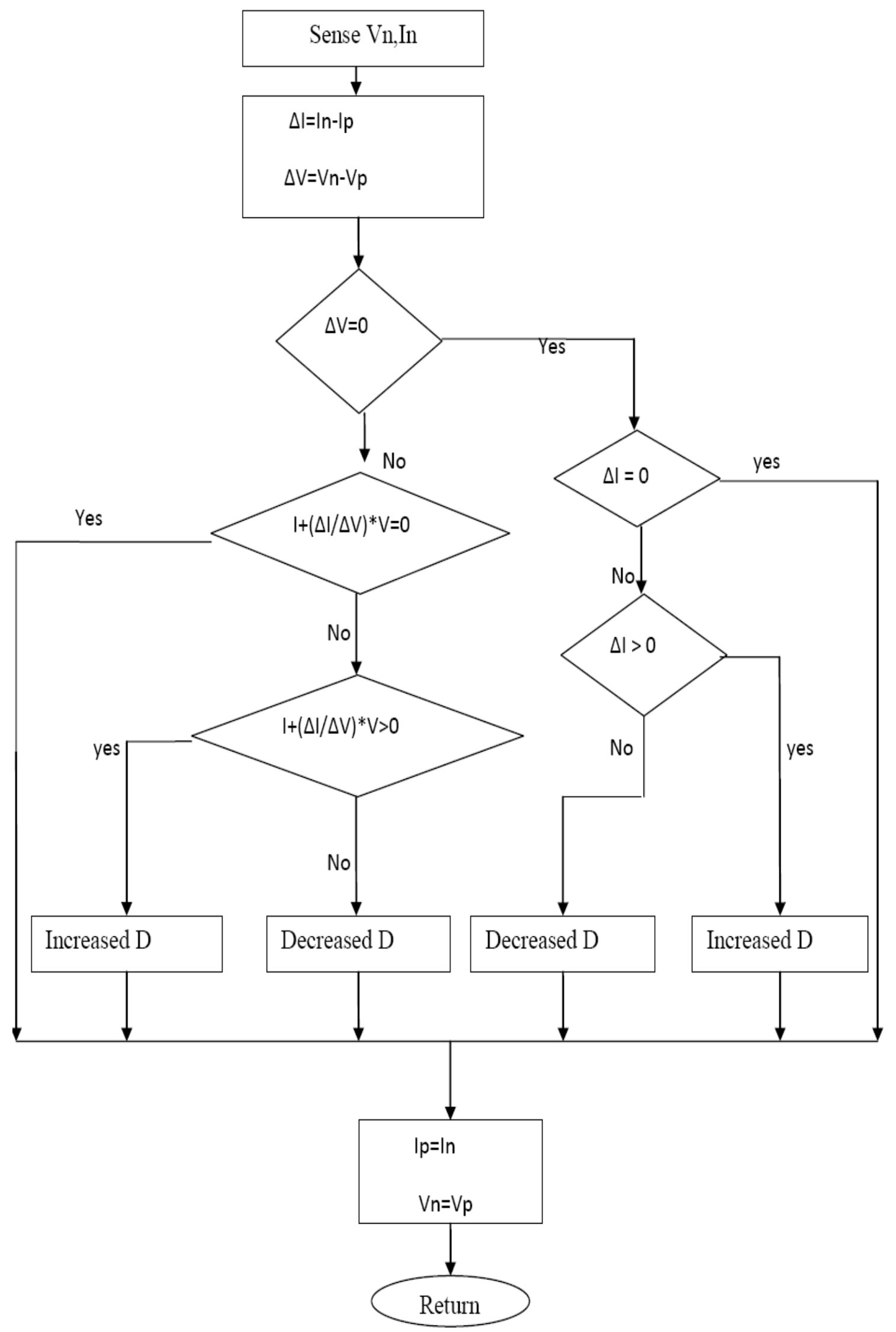

Figure: 13 Flowchart of the tracking Algorithm 
The Voltage $\mathrm{dV}=0$ means panel voltage has not changed. Now the only useful information about possible changes can be found from the current measurement. If $\mathrm{dl}$ is equal to zero, the operating conditions have not changed and therefore the adjustment of the system voltage is bypassed. If $\mathrm{dI}>0$, the duty ratio is increased. If $\mathrm{dI}<0$, the duty ratio is decreased. The program then returns and starts tracking again until the MPP is reached. The tracking process duration is few second. But still, if the sample time is reduced in direct duty cycle control the power tracking can be made faster even in the fast varying climate conditions. The maximum duty cycle ratio is set at $90 \%$ and the minimum is at $10 \%$ to avoid power loss, and hence contributes to the inefficient power transfer of the convert

\section{CALCULATIONS}

Our proposed system able to transfer the maximum power to the load by adjusting the duty cycle using impedance matching technique when only input impedances are changes but load impedance are constant..

For Examples, The input impedances are: $\mathrm{Ri}=3.89 \Omega, 3.80 \Omega, 3.90 \Omega, 3.85 \Omega$

The load impedance are:

$$
\mathrm{RL}=100 \Omega
$$

If, $\mathrm{D}=0.80270 .8051 \quad 0.80250 .8038$ solar array.

Then the input \& output impedance are equal and we can transfer the maximum power to the load from are changes.

Our proposed system is also able to transfer the maximum power when input $\&$ load impedances both

For examples, the input impedances are:

\begin{tabular}{|c|c|c|}
\hline $\mathrm{Ri}=3.89 \Omega$ & $3.8 \Omega$ & $3.90 \Omega$ \\
\hline$R L=90 \Omega$ & $95 \Omega$ & $85 \Omega$ \\
\hline If, $\mathrm{D}=0.7921$ & 0.8000 & 0.7858 \\
\hline
\end{tabular}

$\begin{array}{rrrrr}\text { For example, the load impedance changes are: } \mathrm{RL}= & 90 \Omega & 95 \Omega & 85 \Omega & 105 \Omega \\ & \text { If, } \mathrm{D}=0.7921 & 0.8000 & 0.7858 & 0.8085\end{array}$

Then the input \& output impedance are equal and we can transfer the maximum power to the load from solar array whatever the changes of input and output impedances.

Our Proposed algorithm able to response whatever the changes of voltage and current are very small or very fast. Our modified algorithm is able to track the maximum power, only if we can adjust the duty cycle.

For example, the input voltage changes are:

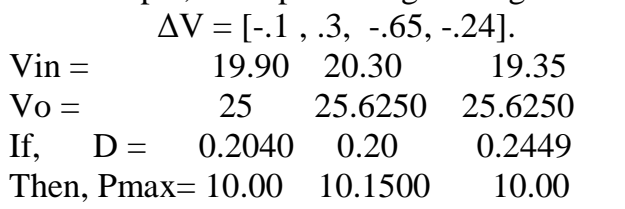

19.76
25.6250
0.2289
10.00

For example, the input current changes are:

\begin{tabular}{lcccc}
\multicolumn{5}{c}{$\Delta \mathrm{I}=[-.03, .05, .022,-.032]}$. \\
Iin $=$ & 0.4700 & 0.5500 & 0.5220 & 0.4680 \\
Io $=$ & 0.4000 & 0.4400 & 0.4176 & 0.4000 \\
If, $\mathrm{D}=$ & 0.1489 & 0.2000 & 0.2000 & 0.1077 \\
Then, Pmax $=$ & 10.00 & 11.000 & 10.4400 & 10.00
\end{tabular}

From above calculations we can see that if we can adjust the duty cycle then we can track the maximum power (never less than $10 \mathrm{~W}$ ), whatever the input voltage and current (weather condition) are continuously changing.

\section{CONCLUSION}

In this paper, a method to optimize the maximum energy extraction from the solar power generation system is proposed. In order to achieve this, the components and subsystems have to be analyzed and validated. The validated models can then be used to maximize the power output of the conversion system.

A high performance technique has been developed to improve the efficiency by extracting the maximum power from the solar energy conversion system. We know when source and load impedance are matched the maximum power will be transfer. Using this concept, DC/DC boost converter has been used to transfer the maximum power by matching the impedance between the source and load which will be controlled by the Duty cycle. Also a program has been developed to track the maximum power for DC/DC boost converter. If the input voltage or current of the DC/DC boost converter (output voltage or current of solar array) decrease the output voltage or current also decrease, that will decrease the power output. But this proposed system will remain the output voltage and current unchanged by adjusting the duty cycle to get the power at least equal to the previous power.

Another development of this research work is the modification of Incremental Conductance method. If the weather condition changed rapidly the modified algorithm can be able to track the maximum power. The benefit of this modification is that it can be able to operate at maximum power point whether the change is very fast or very small. The job of this algorithm is therefore to search the voltage operating point at which the conductance is equal to the incremental conductance. This algorithm has advantages over Perturb and observe that it can determine when the MPPT has reached the MPP, where Perturb and observe oscillates around the 
MPP. Also, incremental conductance can track rapidly increasing and decreasing irradiance conditions with higher accuracy than Perturb and observe.

It can be concluded that, this results has improved efficiency for the operation of solar energy generation systems. This improved efficiency should lead to significant cost saving in the long run.

\section{REFERENCES}

1). C. Hua and C. shen, "Study of maximum power Tracking Techniques and Control of DC/DC converters for Photovoltaic power system,"29 $9^{\text {th }}$ Annual IEEE PESC,IEEE Computer Soc. Press, New York, USA, 1998, pp.86-93.

2). Vindo Kumar Sharma, et al,“ Photovoltaic Technology: Basic Concepts, Sizing of a Stand Alone Photovoltaic system for Domestic Application and preliminary Economic Analysis," Elsevier Science, Energy Conversion and Management, Vol.36, No-3, pp.161-174,1995.

3). Muhammad H.Rashid, Power Electronics, 3rd edition, Prentice-Hall of India, Private Limited, NewDelhi, 2004.

4). Jancarle L. santos, et all, “A maximum Power Point Tracker for PV systems using a high performance boost converter”, Elsevier Science, Solar Energy,vol.80, pp. 772-778, 2006.

5). P. Midya et al, "Dynamic Maximum Power point Tracker for Photovoltaic Applications," $27^{\text {th }}$ Annual IEEE PESC, IEEE Computer Soc. Press, New York, USA, 1998, pp.679-683.

6). A. Kislovski, R. Redl, "Maximum Power Tracking using positive feedback," in Proceedings of IEEE Power Electronics Specialist Conference, 1994,pp. 1065-1068

7). V. Salas et al, "Review of the Maximum power point tracking algorithms for stand-alone photovoltaic systems”, Elsevier Science, solar Energy Materials \& Solar Cells, vol.90, pp.1555-1578, 2006.

8). Hua and J. Lin, "MPPT algorithm for rapidly changing illuminations of solar array," Renewable energy, vol.28, pp.1129-1142, 2006.

9). Hua and J. Lin, "A modify tracking algorithm for maximum power tracking of solar array," Energy Conversion and Management, vol. 45, pp.203-216,2003

10). Neville, R.C., "Solar Energy Conversion," Elsevier Science, 1995. 